\title{
O ATENDIMENTO EDUCACIONAL ESPECIALIZADO DO ESTUDANTE COM DEFICIÊNCIA VISUAL: ENTRE A MEDIAÇÃO DO SISTEMA BRAILLE E AS TECNOLOGIAS COMPUTACIONAIS
}

\author{
Specialized educational care of students with visual deficiency: between the braille \\ system mediation and the computer technologies
}

\section{El atendimiento educacional especializado del estudiante con discapacidad visual: entre la mediación del sistema braille y las tecnologías computacionales}

\author{
José Aparecido da Costa* \\ Celi Corrêa Neres* \\ Nesdete Mesquita Corrêa*
}

\begin{abstract}
Resumo
No Brasil, a defesa pela inclusão de pessoas com deficiência em escolas comuns tem-se ampliado nas duas últimas décadas. Todavia, o pleno acesso e a permanência dessa população à escola pública brasileira ainda são um desafio enfrentado em face ao contingente de pessoas com deficiência que se encontra fora dela. Este estudo teve por objetivo investigar como os estudantes com deficiência visual (cegueira) têm acessado o uso do Sistema Braille e das tecnologias computacionais no Atendimento Educacional Especializado (AEE) realizado em salas de recursos multifuncionais em escolas da rede estadual de Campo Grande, capital de Mato Grosso do Sul. Para tanto, adotou-se a perspectiva sócio-histórica como referencial teórico, indicando uma análise da realidade objetiva sobre as condições presentes no referido atendimento. A coleta de dados se deu por meio de entrevista semiestruturada, com a participação de seis estudantes com deficiência visual (cegueira). Os resultados apontaram fatores relevantes quanto aos recursos disponíveis para o desenvolvimento do processo de escolarização de pessoas com deficiência visual (cegueira). No entanto, ainda é preciso avançar no que tange às possibilidades de acesso a esses recursos como mediadores do processo de ensino e aprendizagem das estudantes.
\end{abstract}

PALAVRAS-CHAVE: Sistema braille. Tecnologias computacionais. Estudantes com deficiência visual

\footnotetext{
* Mestre em Educação pela Universidade Estadual de Mato Grosso do Sul (UEMS). Técnico do Laboratório de Educação Especial e Acessibilidade da UEMS. Doutorando pelo Programa de Pós-Graduação em Educação (PPGEDU) da Faculdade de Educação - FAED, da Universidade Federal de Mato Grosso do Sul (UFMS), Campo Grande, MS.

* Pós-doutora pela Universidade Federal de Mato Grosso do Sul, Campus Pantanal - PPGE/CPAN/UFMS. Doutora em Educação pela Universidade de São Paulo - USP. Docente do Programa de Pós-Graduação Mestrado Profissional em Educação PROFEDUC/UEMS, Universidade Estadual de Mato Grosso do Sul (UEMS), Unidade de Campo Grande, Campo Grande, MS.

* Doutora em Educação pela Universidade Federal de Mato Grosso do Sul - UFMS. Docente do Programa de Pós-Graduação em Educação da UFMS - PPGE/CPAN/UFMS - Campus Pantanal - Corumbá, MS, e da Faculdade de Educação - FAED, da Universidade Federal de Mato Grosso do Sul (UFMS), Campo Grande, MS.
} 


\begin{abstract}
In Brazil, the defense of the inclusion of people with disabilities in common schools has expanded in the last two decades. However, this population's full access and permanence in the Brazilian public schools is still a challenge faced in reason of the great contingent of people with disabilities who are outside it [the school system]. This study aimed to investigate how students with visual impairment (blindness) have accessed the use of the braille system and computer technologies in the Specialized Educational Assistance (AEE) held in multifunctional resource rooms in state network's schools of Campo Grande, Mato Grosso do Sul's capital. For that, the socio-historical perspective was adopted as theoretical reference, indicating the analysis of the objective reality of the conditions present in the referred service. Data were collected through a semistructured interview, with the participation of six students with visual impairment (blindness). The results pointed out relevant factors regarding the resources available for the development of the schooling process of people with visual impairment (blindness). However, it is still necessary to move forward regarding the possibilities of access to these resources as mediators of the teaching and learning process of students.
\end{abstract}

KEYWORDS: Braille system. Computational technologies. Students with visual impairment

\title{
Resumen
}

En Brasil, la defensa por la inclusión de personas con discapacidad en escuelas comunes se ha ampliado en las dos últimas décadas. Sin embargo, el pleno acceso y permanencia de esa población a la escuela pública brasileña sigue siendo un desafío enfrentado frente al contingente de personas con discapacidad que se encuentra fuera de ella. Este estudio tuvo como objetivo investigar cómo los estudiantes con deficiencia visual (ceguera) han accedido al uso del Sistema Braille y de las tecnologías computacionales en el Atendimiento Educativo Especializado (AEE) realizado en salas de recursos multifuncionales en escuelas de la red estatal de Campo Grande, capital de Mato Grosso do Sul. Para ello, se adoptó la perspectiva socio-histórica como referencial teórico, indicando el análisis de la realidad objetiva de las condiciones presentes en el dicho servicio. La captura de datos se dio por medio de una entrevista semiestructurada, con la participación de seis estudiantes con deficiencia visual (ceguera). Los resultados apuntaron factores relevantes cuanto a los recursos disponibles para el desarrollo del proceso de escolarización de personas con discapacidad visual (ceguera). Sin embargo, todavía hay que avanzar en lo que se refiere a las posibilidades de acceso a esos recursos como mediadores del proceso de enseñanza y aprendizaje de las estudiantes.

PALABRAS CLAVE: Sistema braille. Tecnologías computacionales. Estudiantes con discapacidad visual

\section{INTRODUÇÃO}

No Brasil, a defesa pela inclusão de pessoas com deficiência em escolas comuns tem-se ampliado nas duas últimas décadas por meio de políticas públicas do governo federal direcionadas para esse fim. Todavia, o pleno acesso e a permanência dessa população à escola pública brasileira ainda são um desafio enfrentado em face ao contingente de pessoas com deficiência que se encontra fora da escola comum e, quando 
inserida no sistema público de ensino, necessita de condições adequadas para receber os atendimentos educacionais especializados.

A política educacional em curso no Brasil orienta que os alunos com deficiência sejam matriculados nas escolas regulares/comuns ${ }^{1}$ e define que a educação especial, por meio do Atendimento Educacional Especializado (AEE), é responsável pela complementação e/ou suplementação da educação de estudantes com deficiência no ensino comum. As salas de recursos multifuncionais têm sido consideradas por parte do governo federal, nos últimos anos, como locus privilegiado para efetivação do AEE (BRASIL, 2008).

Historicamente, o Sistema Braille ${ }^{2}$ foi reconhecido como forma de escrita capaz de promover o acesso de pessoas com deficiência visual à comunicação e à informação. Atualmente, o acesso às tecnologias computacionais e aos programas sintetizadores de voz tem se apresentado como ferramentas importantes no desenvolvimento acadêmico de estudantes com deficiência visual. Dentre esses, destacam-se: o sistema operacional Dosvox; o Programa leitor de telas NVDA e o Programa Mecdaisy.

Assim, este artigo teve por objetivo discutir como os estudantes com deficiência visual (cegueira) têm acessado o Sistema Braille e as tecnologias computacionais no AEE, realizado em salas de recursos multifuncionais em escolas da rede estadual de Campo Grande, capital de Mato Grosso do Sul (MS). Para tanto, adotou-se como referencial teórico a abordagem sócio-histórica e, para a coleta de dados, utilizou-se como procedimento principal a entrevista semiestruturada com seis estudantes com deficiência visual/cegueira, que, em algum momento no processo de escolarização, tiveram a oportunidade de acessar o Sistema Braille e os programas computacionais.

Ao eleger esses critérios para o desenvolvimento desta pesquisa, tencionou-se investigar como se tem dado o acesso a esses estudantes ao Sistema Braille e às tecnologias computacionais, observadas as diretrizes e delimitação do AEE.

$\mathrm{Na}$ análise dos dados, foram considerados dois eixos (A e B): Eixo $\mathrm{A}$ - acesso ao Sistema Braille e aos programas computacionais, voltados à usabilidade de pessoas com deficiência visual; Eixo B - acesso ao material didático nos formatos braille e/ou digitalizado e desenvolvimento prático atinente ao processo de avaliação.

Os estudantes com deficiência visual contam, hoje, com uma série de possibilidades para que lhes seja assegurado o acesso a diversos materiais de cunho informativo e pedagógico, tais como: o próprio Sistema Braille, o sistema operacional DOSVOX, leitor de tela NVDA e tocador MECDAISY. No entanto, vale questionar como tem sido esse acesso e se os atendimentos educacionais especializados estão realmente habilitados para proporcionar o acesso a tal profusão de recursos, respeitadas a autonomia e suas necessidades educacionais.

\section{Principais recursos incidentes no processo de escolarização do estudante com deficiência visual: do Braille às tecnologias computacionais}

O Sistema Braille foi criado pelo francês Louis Braille em 1825 e teve sua versão definitiva publicada em 1837. Historicamente, o braille foi reconhecido como forma de escrita capaz de promover o acesso de pessoas com deficiência visual à comunicação e à

\footnotetext{
${ }^{1}$ Escolas regulares/comuns são definidas como aquelas que não são especiais.

${ }^{2}$ O Sistema Braille foi criado pelo francês Louis Braille em 1825 e teve sua versão definitiva publicada em 1837 (BAPTISTA, 2000).
} 
informação, e, para ser eficaz, fundamentalmente, teria que se basear na representação em relevo. Esse código consiste na representação em relevo de 63 combinações que, por intermédio destas, é possível se inserir a representação completa do alfabeto, das notações musicais, simbologia matemática, pontuação e acentuação gráfica (COSTA, 2016).

O Sistema braille foi introduzido no Brasil em 1854 com a criação do Instituto Imperial para os Jovens Cegos, atual Instituto Benjamin Constant (IBC), vinculado ao Ministério da Educação (MEC). O nosso país foi um dos primeiros a reconhecer e difundir o Sistema braille. Entretanto, dentre as características inerentes a esse Sistema, destaca-se a pequena rentabilidade no que se refere à utilização do espaço padrão utilizado no papel. Assim, se tem em média, o uso de quatro folhas em braille para uma única escrita em tinta (COSTA, 2016).

Sobre as possibilidades de realização de leituras por meio do Sistema braille, é relevante sublinhar que, embora tenha havido uma ampliação de materiais nos últimos anos no Brasil, o acervo de obras, livros didáticos, textos acadêmicos e outros materiais ainda é pequeno.

No que tange à produção de materiais em braille, Costa e Neres $(2015$, p. 13) salientam que no Brasil, há que se destacar a "escassez de impressoras Braille, e a restrita atuação de profissionais especializados na manutenção destas. Esta realidade acaba por impactar de forma enfática na diminuta produção de conteúdos no referido sistema".

O uso da tecnologia de informação e comunicação para as pessoas com deficiência visual teve suas primeiras iniciativas, recentemente. Estudos apontam que, no Brasil, a utilização de computadores pelas pessoas cegas, desenvolvendo algum tipo de interação em relação homem/máquina, aconteceu na década de $1970^{3}$. Naquele momento, "algumas pessoas com deficiência visual foram formadas em programação, e, dessa forma, podemos considerar essa iniciativa como marco inicial da usabilidade de ferramentas computacionais por pessoas cegas no Brasil" (COSTA; NERES, 2015, p. 14).

Duas décadas depois, o advento do Sistema operacional Dosvox, sistema computacional baseado no uso intensivo de síntese de voz, possibilitou que diversos estudantes com deficiência visual despertassem para a usabilidade das tecnologias computacionais. Esse sistema foi desenvolvido pelo Professor José Antônio dos Santos Borges, no Núcleo de Tecnologias Educacionais da Universidade Federal do Rio de Janeiro, em 1992, em função de atender a necessidade do seu aluno, o estudante com deficiência visual, Marcelo Pimentel. Conforme Borges (2009, p. 112):

Em agosto de 1993, no segundo período, Marcelo foi inscrito num curso obrigatório: Computação Gráfica. Eu lecionava esta disciplina, e diante do contrassenso de um cego fazendo um curso sobre manipulação de informações visuais, perguntei se Marcelo gostaria de ser isento desta disciplina, mas ele insistiu em fazer o curso [...].

De início, o dispositivo foi comercializado em baixo valor, mas, hoje, em função dos investimentos públicos, pode ser adquirido sem qualquer custo e seu uso foi disseminado, uma vez que, por meio dele, é possível notar o aumento na capacidade de interação e comunicação das pessoas com deficiência visual. Esse sistema operacional tem

\footnotetext{
3 Ver NASCIMENTO, L. Os primeiros programadores cegos do Brasil. Disponível em: <http://www.adeva.org.br/jornalconviva/artigo_detalhe.php?jornal=65\&registro=811 >. Acesso em: 21 nov. 2014
} 
ajudado o desenvolvimento das pessoas cegas em atividades diversas, no trabalho e nos estudos.

Atualmente, encontram-se disponíveis também outros programas que permitem às pessoas com deficiência visual acessar informações e ampliar a comunicação por meio do uso do computador. Dentre esses destacam-se os leitores de tela, que geralmente dependem de aquisição de licenças para utilização, pois apresentam leitor de tela de código fechado.

Entre as exceções dos leitores de telas de código fechado, encontra-se o Non Visual Desktop Access - NVDA; na língua inglesa, sua sigla significa "acesso não visual ao ambiente de trabalho". Trata-se de ferramenta de código aberto que funciona no Sistema Operacional Windows, e, por isso, vem ganhando enorme interesse por parte das pessoas com deficiência visual em todo o país (COSTA, 2016).

O programa foi desenvolvido em meados de 2006 por iniciativa do australiano Michael Curran, que se tornou cego quando cursava o segundo ano do bacharelado em Ciência da Computação, em razão de um acidente e, para poder ter acesso à abrangência da vida profissional e à formação acadêmica, teve que realizar a aquisição de um programa leitor de telas profissional com custo elevado. A aproximação com muitas pessoas com deficiência visual, em diversos países, o levou a perceber a necessidade de buscar soluções assistivas não vinculadas ao aspecto comercial (COSTA, 2016).

No tocante ao acesso à produção didática, é uma ferramenta que responde de forma eficiente a essa necessidade, pelo fato de que o referido leitor de telas interage com as principais extensões produzidas em formato digitais ou digitalizados. Destaca-se que o mesmo não ocorre com o Dosvox, que, apesar de disponibilizar uma considerável gama de jogos de cunho pedagógico, para efeito do desenvolvimento de leituras de textos, sua capacidade limita-se aos arquivos com a extensão $t x t$.

Ainda no rol dos recursos disponíveis a serem utilizados pelos estudantes com deficiência visual, tem-se, ainda, o Mecdaisy, um programa para geração de livros digitais falados que permite sua reprodução em áudio, gravada ou sintetizada. O programa foi criado no Brasil, em 2009, pelo governo federal, por intermédio do MEC, em parceria com a Universidade Federal do Rio de Janeiro, com o objetivo de oportunizar o acesso da pessoa com deficiência visual ao livro digital, seja ela cega ou com baixa visão, uma vez que o programa possibilita a utilização de fonte até o tamanho 48 (COSTA, 2016).

Essa iniciativa possibilitou a implantação de uma solução tecnológica que permite a produção de livros em formato digital acessível, com base no padrão Daisy. Naquela ocasião, a plataforma Daisy já contava com considerável difusão, já que, na Suécia, onde foi desenvolvida inicialmente, o governo estabeleceu como meta a disponibilidade de $25 \%$ da produção didática no formato Daisy (COSTA, 2016).

As tecnologias disponíveis hoje podem se traduzir em ferramentas importantes para a escolarização dos estudantes com deficiência visual. Assim, investigar como tem sido esse acesso e se os atendimentos educacionais especializados estão realmente habilitados para proporcionar o acesso a tal profusão de recursos é de fundamental importância no desenvolvimento de pesquisas no campo da educação especial, ênfase deste estudo.

\section{O atendimento educacional especializado, a mediação do Sistema Braille e as tecnologias computacionais: o que revelam os dados da pesquisa}

Para além do ambiente educacional, foco precípuo deste trabalho, destacam-se impactos consideráveis também no que concerne à expansão de possibilidades para a 
pessoa com deficiência visual nos diversos aspectos da esfera social, conforme Caiado (2006, p. 9): "Sobre os avanços científicos, há uma mudança de paradigma na análise das minorias, que não são mais vistas como intrinsecamente incapazes, mas como vítimas da falta de acesso aos direitos sociais".

Analisando os estudos de Vygotski (1997), percebe-se que a interação construída a partir das experiências e a autonomia da pessoa cega são condições cruciais de inclusão social e, nesse sentido, os instrumentos e recursos que podem ser tomados para essa construção são de suma importância na sua escolarização. Sobre esse aspecto, o autor chama atenção, declarando que: "[...] tanto el desarrollo como la educación del niño ciego no tienen tanta relación con la ceguera en si misma, como con las consecuencias sociales de la ceguera". (VYGOTSKI, 1997, p. 18).

Nesse contexto, há necessidade da ressignificação da prática pedagógica, a partir da concepção do locus no qual possa ser compatível a oferta de recursos pedagógicos que efetivamente tenham a propensão a se inserir no cotidiano do estudante com deficiência visual, ressignificado que, ao ser internalizado, promova a percepção da pertença social. $\mathrm{O}$ sujeito se apropria do conhecimento historicamente acumulado com base na convivência social pela internalização de seus significados. Nesse sentido, Caiado (2006, p. 39) pontua que:

[...] biologicamente, a cegueira é muito limitadora, porque ela impede a pessoa de se locomover, explorar novos espaços e receber informações visuais. Porém, socialmente, ela não é limitadora, porque a pessoa cega, pela palavra, pela comunicação com o outro, apropria-se do real ao internalizar os significados culturais.

Em tal perspectiva, julga-se fundamental que ocorra a interação dos profissionais que atuam no ensino comum com aqueles que atuam no AEE, especificamente na sala de recursos multifuncionais, bem como de que os estudantes com deficiência visual tenham acesso ao referido atendimento.

$\mathrm{Na}$ prática pedagógica no âmbito do AEE, apesar da restrição na inter-relação social do estudante com deficiência visual decorrente do processo histórico ser focado na deficiência e não nas limitações contidas no meio, ratifica-se a necessidade de os jogos e aplicativos computacionais serem estimulados quanto ao seu efetivo emprego, a partir de concepção ressignificada da ação pedagógica, de acordo com Vygotski (1997, p. 107): "[...] si los procesos de compensación no estuviesen orientados por la comunicación con los videntes y la exigencia de adaptarse a la vida social, si el ciego viviese sólo entre ciegos, únicamente en este caso podría originarse a partir de él un tipo particular de ser humano".

Para compreender como o estudante com deficiência visual tem acessado o Sistema Braille e as tecnologias computacionais no Atendimento Educacional Especializado (AEE), foram selecionados seis estudantes que frequentavam salas de recursos multifuncionais em escolas da rede estadual de Campo Grande, capital de Mato Grosso do Sul. Como procedimento de coleta de dados, utilizou-se da entrevista semiestruturada. Visando assegurar o sigilo quanto às identidades dos estudantes participantes, foram atribuídas as seguintes formas de identificação: E1, E2, E3, E4, E5 e E6. Há que ressaltar que o contato inicial com os participantes foi realizado via telefone, ocasião em que foi feito o convite para participar da pesquisa. Mediante o aceite, cada participante assinou o Termo de Consentimento Livre e Esclarecido (TCLE).

No que diz respeito às características, os participantes apresentaram idade entre 
dezesseis e cinquenta e quatro anos, sexo feminino, matriculadas em quatro escolas da rede estadual de Mato Grosso do Sul, em Campo Grande, que, em algum momento de suas trajetórias, tiveram a oportunidade de frequentar atendimento em instituição especializada.

Das estudantes entrevistadas, três se encontravam matriculadas no Ensino Médio, e três, na mesma etapa, mas na modalidade Educação de Jovens e Adultos (EJA).

Ressalta-se que houve dificuldade para identificar essas seis estudantes nessa etapa da Educação Básica, devido ao reduzido número de estudantes com deficiência visual que frequentam esse nível de ensino. Portanto, o estudo limitou-se àqueles estudantes que tivessem propensão à utilização de programas leitores de tela, no que concerne ao acesso ao processo de leitura e escrita.

Para organizar os dados coletados nas entrevistas, optou-se por se estruturar o conteúdo por eixos de análise, que serão abordados na próxima sessão.

\section{Eixo A - acesso ao Sistema Braille e aos programas computacionais, voltados à usabilidade de pessoas com deficiência visual}

No quesito usabilidade do Sistema Braille e utilização de ferramentas computacionais, deparou-se com a seguinte realidade: no que tange ao processo de alfabetização, quatro das seis estudantes foram alfabetizadas tendo como meio de escrita e leitura o Sistema Braille. Do total de participantes da pesquisa, duas foram alfabetizadas na escrita em tinta, uma vez que até a adolescência mantiveram a possibilidade da referida prática, na medida em que possuíam acuidade visual compatível com tal utilização.

Registra-se que das seis estudantes participantes desta pesquisa, duas informaram que desenvolviam suas atividades correlatas à escolarização exclusivamente por intermédio do Sistema Braille. Três desenvolviam seus estudos com a mediação tanto do Sistema Braille, quanto dos programas computacionais que possibilitam a interação com as pessoas com deficiência visual.

$\mathrm{Na}$ análise, identificou-se a seguinte situação relativa ao acesso às grafias para a produção braille. Das seis estudantes, E1 e E2 afirmaram que nunca tiveram qualquer contato direto com as grafias da escrita braille. Já as estudantes E3 e E4 informaram que conhecem ou já tiveram algum acesso às grafias braille da Língua Portuguesa e da Matemática. Enquanto que E5 esclareceu que teve acesso às grafias mencionadas pelas estudantes anteriores, acrescentando que também teve contato com a grafia para a Química. Por sua vez, a estudante E6, em razão de se encontrar, na ocasião da pesquisa, em processo de aprendizagem do Sistema Braille, não teve acesso a qualquer das grafias.

Encontra-se vigente um conjunto de documentos normativos de grafias braille com os respectivos símbolos/códigos que compreendem: Grafia Braille para a Língua Portuguesa, Grafia Braille para a Matemática (o CMU), Grafia Braille para a Química, Grafia Braille para a Informática, Estenografia Braille para a Língua Portuguesa, Grafia Braille para a Música ou Musicografia. E, além dessas, as Normas Técnicas para a Produção de Textos em Braille, em cujo teor se encontram as diretrizes genéricas para a edição de publicações na referida escrita.

Todavia, é relevante assinalar que, dentre as seis entrevistadas, nenhuma delas possuía conhecimento de quaisquer documentos mencionados, cujo objetivo é assegurar a produção da escrita braille com a restrita observância de normas relativas ao Sistema Braille. 
É fundamental apontar que o restrito acesso dessas estudantes às respectivas grafias incidiu na redução de oportunidades de aprendizagem, sobretudo pelo fato de o acesso às mesmas ter ocorrido somente na sala de recursos e no máximo a três grafias, como apontaram os dados desta pesquisa, o que não possibilitou a usabilidade do Sistema Braille com melhor domínio.

Ao tratar da utilização da informática com ênfase em recursos computacionais disponíveis para uso por pessoas com deficiência visual, observada aqui a condição de vínculo com o processo de escolarização dos estudantes com deficiência visual, ressalta-se que, dentre as seis estudantes entrevistadas, E1 afirmou não conhecer essas ferramentas computacionais. Ao passo que E2 declarou que, no momento da pesquisa, se encontrava no início do estudo dos programas que permitem a interação de pessoas com deficiência visual para a usabilidade do computador.

A estudante E6 informou que, em algum momento do seu processo de escolarização, teve contato com um programa computacional com as características que se enquadram no presente estudo. Entretanto, não soube precisar o nome dessa ferramenta. As três outras estudantes afirmaram que utilizavam o computador e os programas que são voltados para o uso de pessoas com deficiência visual; dessas, duas informaram que usufruíam do Jaws e Dosvox e uma usufruía do Jaws e do NVDA.

Ao serem inqueridas sobre a preferência por uma das formas de acesso ao desenvolvimento do processo de escolarização, das três estudantes que informaram que realizam seus estudos de forma concomitante, considerados o Sistema Braille e as ferramentas computacionais, duas disseram preferir a utilização da mencionada forma de escrita, já que, desta maneira, podiam sentir as letras, os pontos, as palavras, a pontuação e a acentuação gráfica, e isso lhes conferia mais confiabilidade no ato do exercício da leitura e escrita. A outra estudante afirmou que preferia o uso do computador, uma vez que, se fosse depender do livro transcrito para o Sistema Braille, só teria acesso a esse após muito tempo, fator que implicaria prejuízo em seus estudos. E que, portanto, na unidade escolar em que estudava, conseguia o material didático digitalizado de forma muito mais rápida.

Aqui se apresenta de maneira explícita, a dificuldade que estudantes com deficiência visual encontram para o acesso às produções de textos em braille. Os dados de pesquisa apontam que mesmo com a implantação do Centro de Apoio Pedagógico ao Deficiente Visual, CAP-DV, em MS, desde o final dos anos 1990, para a produção de material adaptado para esses estudantes, essa situação não se modificou. Isto requer, portanto, medidas que devem ser adotadas para esse fim pelo poder público, já que em tempos de proposta de educação inclusiva - a educação para todos, este estudo ao desvelar tais aspectos aponta para uma inconsistência com a referida proposta.

Também indagou-se às entrevistadas como participavam das aulas de informática ministradas na escola: E1, E2 e E3 declararam que, na escola em que estudavam, não havia oferta de informática. Enfatizaram que como frequentavam a EJA, nessa modalidade não havia a disponibilização de conteúdo de informática na proposta curricular.

Por sua vez, as estudantes que frequentavam três outras unidades escolares afirmaram que, nas salas de tecnologia, os computadores não contavam com programas leitores de telas instalados. Em face de tal circunstância, quando participavam das referidas aulas, o faziam em duplas, com o auxílio de colegas das respectivas turmas. Ressalta-se que isso ocorreu com as três estudantes, entretanto, dentre elas, uma expôs que não tem domínio de qualquer uma das ferramentas computacionais, ou seja, a falta de participação não se vinculava apenas à ausência de programas leitores de telas nos computadores.

Enfatiza-se ainda que, dentre as duas estudantes que indicaram conhecimento das 
ferramentas computacionais que permitem a utilização por pessoas com deficiência visual, somente uma delas informou que utilizava o computador na sala de recursos multifuncionais ou em sua casa. Portanto, não o fazia na sala de aula do ensino comum. A estudante, ao ser questionada sobre essa situação, respondeu que o computador lhe provocava "falta de concentração" no desenvolvimento das atividades lá produzidas.

Todavia, no decorrer da pesquisa, ao se realizar entrevista com a mesma estudante em sala de recursos multifuncionais, foi constatado que ela utilizava o computador nos momentos em que frequentava essa sala, cujo espaço coletivo não favorecia o silêncio absoluto, da mesma forma como na sala de aula do ensino comum. Assim, a alegada "falta de concentração" pela estudante para o não uso do computador na sala de aula do ensino comum não ficou devidamente esclarecida.

\section{Eixo B - acesso ao material didático nos formatos braille e/ou digitalizado e desenvolvimento prático atinente ao processo de avaliação}

No que se refere ao acesso ao material didático, três das seis estudantes entrevistadas informaram que na modalidade EJA, por elas frequentada, o sistema era apostilado. Dentre elas, duas afirmaram que sempre receberam os textos das disciplinas e uma apontou que, por vezes, recebia o conteúdo com atraso, de maneira especial, quando se tratava da disciplina de Língua Portuguesa.

Dentre as outras três estudantes, uma declarou que recebia os materiais por etapa, pois o tempo não era suficiente para que os docentes que atuavam na sala de recursos pudessem produzir e disponibilizar os livros didáticos em braille na íntegra. Dessa forma, a estudante E4 informou que os professores da sala de recursos, por meio da interação com os docentes do ensino comum, iam atualizando os conteúdos. Acrescentou a estudante que esse procedimento era bastante funcional, pois, via de regra, ela conseguia receber o material em tempo hábil.

A estudante E5 relatou que tinha acesso aos livros por meio do computador e que a própria equipe da unidade escolar, onde estudava, se responsabilizava pela disponibilização dos livros didáticos digitalizados, ainda que de forma particionada. Isto é, na medida em que a turma se apropriava de novos conteúdos, a equipe da escola disponibilizava-os para ela.

A estudante E6 foi taxativa ao afirmar que não contava com qualquer forma de acesso ao material didático, quando informou: "Eu não uso livro didático. Eu só fíco ouvindo o que os professores falam. Uma colega de sala faz a leitura para mim. Ela percebeu que eu fico triste e passou a ler para mim". Diante de tal circunstância pode-se depreender que, por vezes, o próprio sistema educacional acaba por não realizar a produção do material didático de maneira satisfatória para o conjunto de estudantes com deficiência visual.

Em épocas anteriores, quando o material didático não era produzido nos formatos braille e/ou digitalizado, possivelmente, a estudante teria ao menos um gravador disponibilizado para o seu uso e fitas cassetes com as gravações dos componentes curriculares. Ainda que a estudante estivesse vivenciando a transição para a utilização do Sistema Braille, ela não ficaria desprovida da mínima condição para o desenvolvimento dos estudos. Portanto, isso indica que mesmo em tempos de tecnologias mais sofisticadas e de proposta de educação inclusiva, há um descompasso, pela insuficiência na oferta do material didático nos formatos braille e/ou digitalizados. 
Ainda com relação ao acesso ao livro didático, é significativo o fato de que das seis estudantes entrevistadas, somente uma afirmou ter algum conhecimento sobre o programa Mecdaisy. Como já destacado neste estudo, o Mecdaisy é uma ferramenta computacional desenvolvida com o objetivo de oportunizar o acesso da pessoa com deficiência visual ao livro digital, seja ela cega ou com baixa visão, uma vez que o programa possibilita a utilização de fonte até o tamanho 48. No entanto, dentre os estudantes que participaram desta pesquisa, não se verificou o emprego do referido programa.

Diante dessa constatação, se de um lado os dados indicados neste estudo revelaram certa prevalência pelo uso do Sistema Braille, por outro lado, também apontaram que três das estudantes entrevistadas tiveram contato inicial com a informática; e que em algum momento do processo de escolarização pararam seus estudos, sendo que posteriormente, apenas uma delas conseguiu retomá-los, com a queixa da falta da oferta de cursos de informática.

Ao indagar as estudantes sobre o processo avaliativo, deparou-se com o relato de formas diversificadas para atender a esse procedimento formal nas unidades escolares. Todavia, a pesquisa revelou que metade delas realizava as avaliações por intermédio do Sistema Braille. Para tanto, geralmente, os professores da sala de recursos multifuncionais recebiam as avaliações com antecedência para a efetivação da transcrição para o Sistema Braille. Posteriormente, as avaliações eram realizadas com os demais colegas de turma.

Uma das estudantes assegurou que a avaliação de algumas disciplinas, como a Matemática, era desenvolvida no computador. Também, afirmou que as outras eram realizadas de forma oral. Ainda, outra estudante relatou não ter realizado qualquer processo avaliativo até a data da realização da entrevista, uma vez que na EJA a avaliação era agendada no momento em que o estudante se sentia seguro para tal, e que ela, ainda, marcaria a primeira avaliação.

Outra estudante declarou que, por não ter o domínio do Sistema Braille nem dos programas computacionais com a interface da acessibilidade, não realizava as avaliações. Ela afirmou que a exceção se dava em relação à disciplina Biologia, pois, nesse caso, a professora the apresentava algumas perguntas. Diante da explicação da estudante, foi-lhe perguntado como obtivera suas notas até o momento da entrevista, quando respondeu que os professores lhe atribuíam nota seis e, às vezes, sete. Afirmou, ainda, que frequentemente sua família the cobrava notas mais elevadas, alegando que elas eram boas, mas que ela poderia obter outras notas melhores.

Ressalta-se que, também no quesito avaliação, a interação de professores da sala de aula do ensino comum com professores da sala de recursos multifuncionais se apresentou de forma satisfatória, pois, ao menos para a metade das estudantes participantes desta pesquisa, essa medida se manifestou no desenvolvimento da ação docente.

\section{CONSIDERAÇÕES FINAIS}

Este artigo, ao ter por objetivo discutir como os estudantes com deficiência visual (cegueira) têm acessado o Sistema Braille e as tecnologias computacionais no AEE realizado em salas de recursos multifuncionais em escolas da rede estadual de Campo Grande, revelou dados que expressam necessidade de mudanças no processo de escolarização desses estudantes.

Diante dos resultados apresentados, refletimos que a primeira providência a ser tomada para que o processo de escolarização de estudantes com deficiência visual tome 
sentido e realidade, no âmbito da proposta de educação inclusiva, é analisar o fenômeno distanciado de concepções simplistas e, portanto, acríticas, uma vez que as constatações extraídas pelo estudo não permitem o acolhimento e a disseminação de tais concepções.

Embora esteja em vigência um conjunto documentos normativos de grafias braille com os respectivos símbolos/códigos que a compreendem, bem como as Normas Técnicas para a Produção de Textos em Braille, é relevante assinalar que, dentre as seis entrevistadas, nenhuma delas possuía conhecimento de quaisquer documentos mencionados, cujo objetivo é assegurar a produção da escrita braille com a restrita observância de normas relativas ao Sistema Braille.

Nas expressões das estudantes entrevistadas, com relação ao acesso ao Sistema Braille, ficou sinalizada a falta de acessibilidade na maioria dos seus documentos normativos, seja no que concerne às grafias, seja no que diz respeito às diretrizes gerais preconizadas para sua adequada produção.

$\mathrm{O}$ fato de, em tempos de tecnologias mais sofisticadas e de proposta de educação inclusiva, ainda haver insuficiência na oferta do material didático nos formatos braille e/ou digitalizados, para as estudantes entrevistadas, evidencia realidades vivenciadas por essas estudantes cuja condição se encontra na contramão das propostas concernentes às políticas de educação inclusiva vigentes no país.

Para além do exposto, na escola do ensino comum, se identificou uma realidade de exclusão escolar, diante da descabida atribuição de notas à estudante com deficiência visual, sem que houvesse sequer a efetivação de sua participação no processo avaliativo, pois dessa forma, apesar de o discurso pretensamente inclusivo, a rigor, as estudantes vêm ocupando locus de categoria que se encontra à margem do processo de escolarização.

Em face da ausência de atendimentos educacionais especializados que permitissem às estudantes entrevistadas a mediação dos recursos pedagógicos pela via das tecnologias computacionais, bem como a não oferta, às estudantes, do acesso ao Sistema Braille e às referidas tecnologias, essenciais para o desenvolvimento do processo de escolarização do estudante com deficiência visual, sobretudo da mediação dos recursos pedagógicos, cabe a seguinte indagação: Será que as lacunas identificadas nas unidades escolares, de forma sistêmica, vão sempre lhes oportunizar, como alternativa restrita, apenas a oralização?

Espera-se que futuros estudos a serem desenvolvidos possam aprofundar a investigação dos resultados apontados nesta pesquisa, e que possibilitem respostas, pelo menos em parte, às indagações registradas.

\section{REFERÊNCIAS}

BAPTISTA, J. A. L. S. A invenção do Braille e a sua importância na vida dos cegos: Louis Braille, 1809-1852. Lisboa: Comissão de Braille, 2000. Não paginado. Disponível em: <http://www.gesta.org/Braille/Braille01.htm>. Acesso em: 22 abr. 2016. BRASIL. Política Nacional de Educação Especial na Perspectiva da Educação Inclusiva. Brasília, 2008. (2008). Disponível em: <http://portal.mec.gov.br/seesp/arquivos/pdf/politica.pdf>. Acesso em: 03 mai. 2016.

BORGES, J. A. S. Do Braille ao DOSVOX: diferenças nas vidas dos cegos brasileiros. 2009. 343 f. Tese (Doutorado em Engenharia de Sistemas e Computação) - Universidade 
Federal do Rio de Janeiro, Rio de Janeiro, 2009. Disponível em:

<http://teses2.ufrj.br/Teses/COPPE_D/JoseAntonioDosSantosBorges.pdf>. Acesso em: 17 nov. 2014.

CAIADO, K. R. M. Aluno deficiente visual na escola: lembranças e depoimentos. 2. ed. São Paulo: Autores Associados, 2006.

COSTA, J. A. O atendimento educacional especializado do estudante com deficiência visual: entre o Braille e as tecnologias computacionais. 2016. (Dissertação de Mestrado Profissional em Educação), Universidade Estadual de Mato Grosso do Sul - UEMS, Programa de Pós-Graduação Stricto Sensu, Campo Grande, 2016.

COSTA, J. A; NERES, C.C. A inclusão escolar de alunos com deficiência sensorial: estudo sobre as tecnologias assistivas. Campo Grande, UEMS, 2015. (Relatório de pesquisa).

NASCIMENTO, L. Os primeiros programadores cegos do Brasil. Disponível em: <http://www.adeva.org.br/jornalconviva/artigo_detalhe.php?jornal=65\&registro $=811>$. Acesso em: 21 nov. 2014.

VYGOTSKI, L. S. Obras Escogidas V: fundamentos de defectología. Madrid: Visor, 1997.

Recebido em: 12/11/2018

Aprovado em: 10/01/2019 